\title{
Non-Inseminated Queens Have Worker-Like Behaviors in Colonies of Fungus-Growing Ants, Mycetomoellerius turrifex Wheeler (Attini, Hymenoptera)
}

\author{
T MURAKAMI \\ Institution of Decision Science for a Sustainable Society, Kyushu University, Fukuoka, Japan
}

\section{Article History \\ Edited by \\ Evandro Nascimento Silva, UEFS, Brazil \\ Received 05 August 2020 \\ Initial acceptance 08 August 2020 \\ Final acceptance 20 August 2020 \\ Publication date 30 September, 2020}

\section{Keywords}

Mating failure, monogyny, polygyny.

\section{Corresponding author \\ Takahiro Murakami \\ Institution of Decision Science for a \\ Sustainable Society \\ Kyushu University \\ Motooka 744, Fukuoka, 819-0395, Japan \\ E-mail: taka_bci2000@yahoo.co.jp \\ murakami.takahiro.023@m.kyushu-u.ac.jp}

\begin{abstract}
In eusocial Hymenoptera such as ants, bees, and wasps, the queen numbers are fundamentally important to maintain the social systems. In Texas, USA, a fungus growing ant, Mycetomoellerius turrifex Wheeler (1903) (the genus name was changed from Trachymyrmex to Mycetomoellerius in 2019 (Solomon et al., 2019)) was observed to have several non-inseminated queens that wandered outside the nest long after the mating season. However, the evolutionary and ecological factors causing the occurrence of such non-inseminated queens are still unclear. Thus, I examined the worker-like behaviors of non-inseminated queens of $M$. turrifex in Texas. Fifteen ant colonies were collected over three years, between 1999 and 2001. The frequencies of non-inseminated queens, workers, and broods, as well as the depths of nest chambers, were observed in each collecting year. In Nov. 1999 and May 2000, multiple nests contained queens that did not mate with males within their nests. These nests had a relatively larger colony size than those collected in Oct. 2001. Conversely, the colonies collected in Oct. 2001 were completely monogynous, i.e., there were no non-inseminated queens in the nests. Behavioral observations of each female revealed that the non-inseminated queens behaved significantly differently from the workers and the inseminated queens. The behaviors that distinguished different female castes were mutualistic fungus garden care, digging of nest floors, guarding, and resting in the nest. These data suggest that queens failed to mate due to severe environmental fluctuations in southern Texas, but were accepted by the colony as a temporary labor force.
\end{abstract}

\section{Introduction}

Typical and simple ant societies consist of an inseminated reproductive queen and multiple infertile workers in one nest (Hölldobler \& Wilson, 1990). The subsequent social transformation steps in ant societies have evolved polydomy (when a colony has multiple nests), polygyny (when multiple inseminated queens are in one nest), polyandry (when a queen mates with multiple males), parasitism (i.e., of another ant species), production of intermediate reproductive females (intercastes, gamergates, and ergatoid queens), and worker reproduction (Peeters \& Ito, 2001). Generally, newly emerged queens conduct nuptial flights or attract males using sexual pheromones and then mate with them. If a queen is unable to mate with males at that point, it will die within a short period of time.

There are a few species in which non-inseminated queens survive and co-exist in their natal nest. For example, the presence of non-inseminated queens within colonies has been reported in Myrmecina nipponica (Ohkawara et al., 1993; Murakami et al., 2002) and Probolomyrmex longinodus (Kikuchi \& Tsuji, 2005), but their behavioral ecology remains poorly studied and the adaptive factors to evolve the existence of non-inseminated queens in their natal nest are still controversial.

Fungus-growing ants (tribe Attini), distributed only in the New World, have a specialized ability to cultivate 
mutualistic fungi in the nest and feed them to queens and larvae (Weber, 1972; Hölldober \& Wilson, 1990; Murakami \& Higashi, 1997; Mueller \& Gerardo, 2002). Attini consists of over 250 species and 17 genera, some of which have a simple colony structure (small colony sizes, monogyny, and no worker polymorphism), such as Mycetosorites, Myrmicocrypta, and Cyphomyrmex, while others have a very complex society (huge colony sizes, multiple fungus cavities deep underground, and highly divided worker polymorphism), such as leaf-cutting ants, Atta, and Acromyrmex.

The genus Mycetomoellerius is the "higher" group that has relatively derived ecological characters and molecular phylogentic positions in Attini (Solomon et al., 2019). They have small to medium colony sizes (around 50-1000 workers in one nest), and their workers are slightly physically differentiated in subcastes. Mycetomoellerius turrifex Wheeler is distributed in Texas, northeastern Mexico, western Louisiana, and Oklahoma. The ant is abundant in the open desert habitats of west Texas and dense populations have been observed in southern Texas. Nests consist of 1-5 chambers connected by vertical tunnels. The colonies are monogynous and have up to 300 workers (Rabeling et al., 2007).

In this paper, I report that this ant is basically functionally monogynous, but they have multiple noninseminated queens in their nests. Colonies of $M$. turrifex in southern Texas were sampled over three years, and individual behaviors of female castes were observed. The roles and functions of non-inseminated queens are discussed, and verified five hypotheses that will explain the existence of noninseminated queens in a natal nest. The hypotheses are related to environmental changes, social parasite strategy, mating strategy, trophic egg production, and labor force in a workerlike manner (Kikuchi \& Tsuji, 2005).

\section{Materials and Methods}

\section{Sample collection}

I collected 15 M. turrifex colonies from 1999-2001 at the Brackenridge Field Laboratory of the University of Texas, U.S.A. $\left(30^{\circ} 17^{\prime} \mathrm{N}, 97^{\circ} 46^{\prime} \mathrm{W}\right)$. Additionally, in 2000 and 2001 , the depths of each fungus garden chamber were measured. At each sampling time, the numbers of workers, queens, pupae, larvae, eggs, and males were counted. Colonies were kept in the laboratory at room temperature with milled corn and oats as their fungus substrates.

\section{Individual behavioral observations}

The behaviors of 34 queens from five colonies and 12 workers from four colonies were observed using a microscope (OLYMPUS SZ-40) and recorded. I observed in detail the queens and the workers after individually marking them with oil-based pen dyes. Their behaviors were checked every $10 \mathrm{~min}$, for five $\mathrm{h}$ in each colony, and the total observation times were $25 \mathrm{~h}$ for queen ants and $20 \mathrm{~h}$ for worker ants.
The recorded behavioral repertoires were divided into 24 types according to Murakami (1998). After the observation period, all queens were dissected under a microscope and their egg laying abilities, oviposition experiences, and existing sperms into spermathecae, were assessed.

\section{Statistical analysis}

In order to analyze the behavioral differences among each caste, canonical discriminant analysis, a type of multivariate analysis, was used to discriminate among three categories: inseminated queens, non-inseminated queens, and workers. The analysis used 24 behavioral repertoires as explanatory variables. This analysis allowed us to identify the discrimination rate for each category and the behavioral repertoire that significantly contributed to discrimination. The analysis was conducted using R (3.6.1) software.

\section{Results}

As shown in Table 1, the frequencies of inseminated queens, non-inseminated queens, workers, and broods changed every collecting year. In November 1999, there were significantly more workers (average: 71.8 individuals \pm 60.9 , $\mathrm{n}=4$ ) than that in other collecting years [one-way ANOVA, Tukey-Kramer test; $\mathrm{t}=1.93, \mathrm{p}=0.17$ for May 2000 (average: $30.5 \pm 18.5, \mathrm{n}=6$ ); $\mathrm{t}=2.77, \mathrm{p}=0.04$ for Oct. 2001 (average: $10.4 \pm 8.6, \mathrm{n}=5)]$. In Nov. 1999 and May 2000, multiple non-inseminated queens were observed in $80 \%$ of collected colonies $(12.8 \pm 14.7$ in $1999,12.3 \pm 10.9$ in 2000$)$. In contrast there were no non-inseminated queens in the colonies in Oct. 2001 (one-way ANOVA, Tukey-Kramer test; $\mathrm{t}=2.18, \mathrm{p}=$ 0.07 , between 1999 and 2001; $\mathrm{t}=2.88, \mathrm{p}=0.01$, between 2000 and 2001). The number of broods (larvae, pupae, and eggs) in May 2000 was significantly larger than that in Nov. 2001 (one-way ANOVA, Tukey-Kramer test; $\mathrm{t}=2.93, \mathrm{p}=0.03$ ). There was no male production except for one colony in 1999 , which reared 13 males. $M$. turrifex had on average three nest chambers per colony. The depths of the first chamber ranged from 3-10 cm, that of the second chamber ranged from 19-56 $\mathrm{cm}$, and the last chamber was over $35 \mathrm{~cm}$ deep. The depths of first chamber were shallower, and that of the second and third chambers were deeper in 2001 compared with those in 2000.

Following detailed behavioral observations, individuals were identified as either queens or workers (Table 2). After the observations, all queens were dissected, and four inseminated queens were identified. Thirty non-inseminated queens did not produce even trophic eggs in the ovarioles. The inseminated queens had never performed any task outside the nests, and their top three behaviors were fungus licking (25\%), resting inside the nests (23.1\%), and antennations $(22.5 \%)$. The non-inseminated queens performed $87.5 \%$ repertoires of all observed behaviors including those of worker ants. Oviposition was never observed in these females. The top three behaviors of the non-inseminated queens were resting 


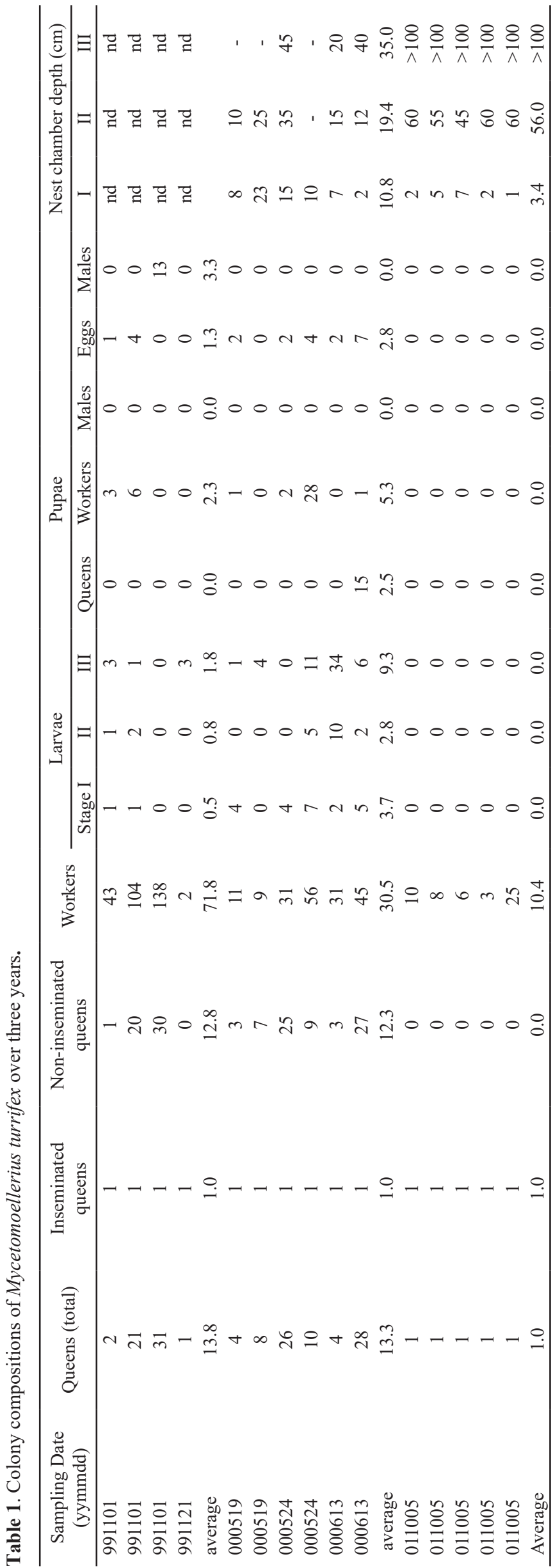

inside the nests (22.6\%), walking inside the nests $(18.8 \%)$, and guarding behavior near the nest entrance (10.8\%). The most frequent worker behaviors were fungus care $(25.6 \%)$, walking outside the nests $(23.1 \%)$, and walking inside the nests $(15.2 \%)$. The twelve workers observed never performed substrate collection, substrate weeding, and brood care. The canonical discriminant analysis using the frequencies of 24 behavioral repertoires and each female category revealed that each category (inseminated queens, non-inseminated queens, and workers) could be divided with a discrimination rate of $100 \%$ (Fig 1; axis 1: Wilks lambda $=0.031$, chi square $=$ 116.04, $\mathrm{df}=40, \mathrm{p}<0.0001$; axis 2 : Wilks lambda $=0.301$, chi square $=40.20, \mathrm{df}=19, \mathrm{p}<0.01)$. The behaviors that strongly contributed to axis 1 were fungus garden care and nest floor digging behaviors, and those strongly contributing to axis 2 were defense behaviors and resting in the nest.

Table 2. The frequencies of behavioral observations in each female caste in Mycetomoellerius turrifex.

\begin{tabular}{|c|c|c|c|}
\hline & $\begin{array}{l}\text { Inseminated } \\
\text { queens }\end{array}$ & $\begin{array}{c}\text { Non-inseminated } \\
\text { queens }\end{array}$ & Workers \\
\hline $\begin{array}{l}\text { Observed individual } \\
\text { numbers }\end{array}$ & 4 & 30 & 12 \\
\hline Collecting substrate & $0(0.0)$ & $8(0.3)$ & $0(0.0)$ \\
\hline Licking substrate & $0(0.0)$ & $70(2.8)$ & $7(0.6)$ \\
\hline Substrate weeding & $0(0.0)$ & $46(1.8)$ & $0(0.0)$ \\
\hline Substrate care & $0(0.0)$ & $14(0.55)$ & $21(1.9)$ \\
\hline Walking outside & $0(0.0)$ & $215(8.5)$ & $255(23.1)$ \\
\hline Self-grooming (outside) & $0(0.0)$ & $33(1.3)$ & $14(1.3)$ \\
\hline Antennation (outside) & $0(0.0)$ & $8(0.3)$ & $0(0.0)$ \\
\hline Resting (outside) & $0(0.0)$ & $3(0.1)$ & $7(0.6)$ \\
\hline Dumping & $0(0.0)$ & $26(1.0)$ & $7(0.6)$ \\
\hline Guarding & $0(0.0)$ & $274(10.8)$ & $18(1.6)$ \\
\hline Allo-grooming & $16(4.4)$ & $4(1.6)$ & $52(4.7)$ \\
\hline Walking inside & $55(15.3)$ & $478(18.8)$ & $168(15.2)$ \\
\hline Antennation & $81(22.5)$ & $229(9.0)$ & $52(4.7)$ \\
\hline Digging & $0(0.0)$ & $0(0.0)$ & $112(10.1)$ \\
\hline Resting (inside) & $83(23.1)$ & $575(22.6)$ & $21(1.9)$ \\
\hline Self-grooming (inside) & $26(7.2)$ & $206(8.1)$ & $63(5.7)$ \\
\hline Cleaning floor & $0(0.0)$ & $69(2.7)$ & $4(0.4)$ \\
\hline Trophallaxis & $1(0.3)$ & $20(0.8)$ & $18(1.6)$ \\
\hline Fungus care & $0(0.0)$ & $14(0.55)$ & $283(25.6)$ \\
\hline Fungus Licking & $90(25.0)$ & $202(8.0)$ & $4(0.4)$ \\
\hline Brood care & $0(0.0)$ & $6(0.2)$ & $0(0.0)$ \\
\hline Carcass care & $0(0.0)$ & $4(0.2)$ & $0(0.0)$ \\
\hline Laval eating & $7(1.9)$ & $0(0.0)$ & $0(0.0)$ \\
\hline Oviposition & $1(0.3)$ & $0(0.0)$ & $0(0.0)$ \\
\hline Total observations & $360(100 \%)$ & $2504(100 \%)$ & $\begin{array}{c}1106 \\
(100 \%) \\
\end{array}$ \\
\hline
\end{tabular}




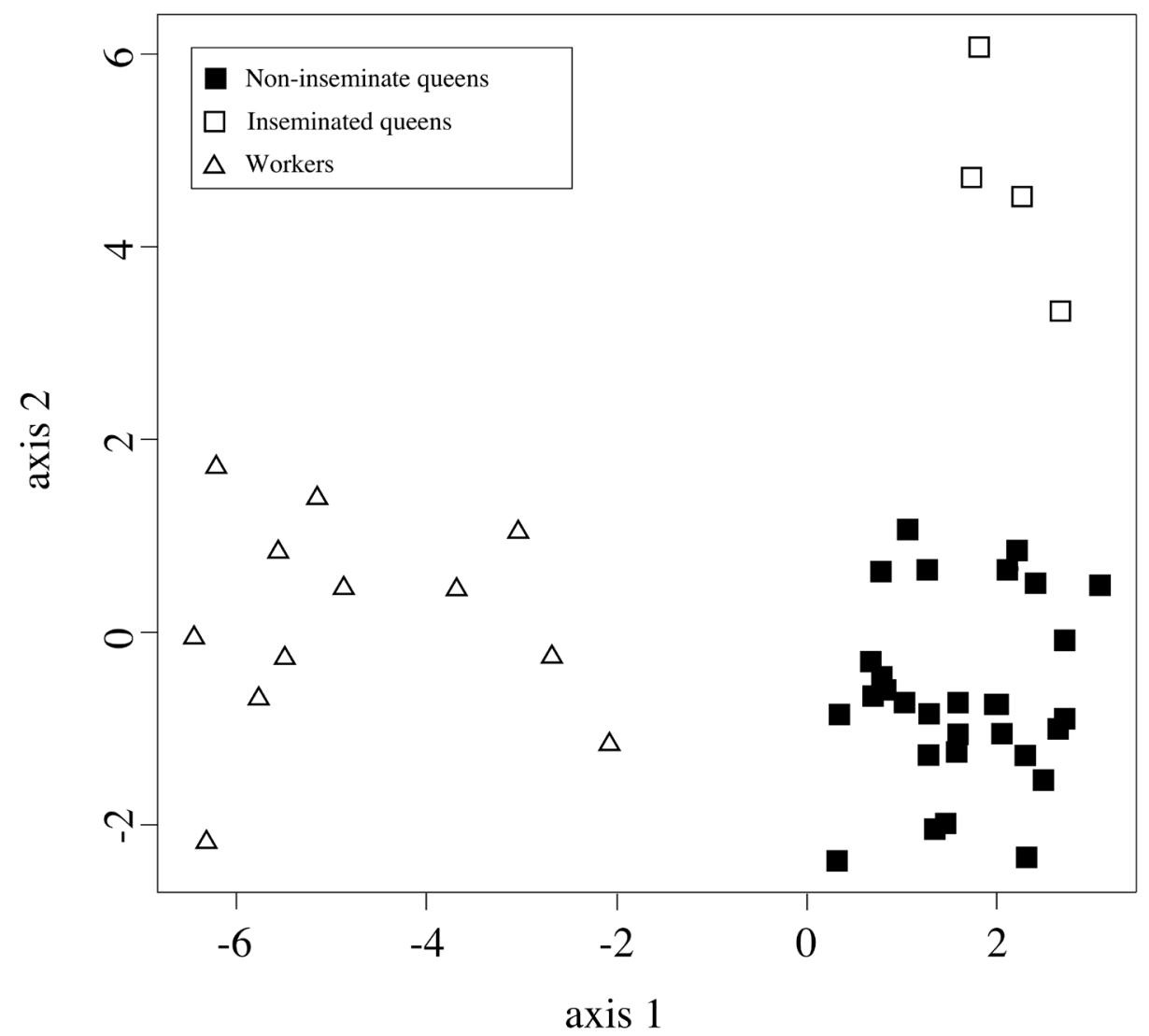

Fig 1. Canonical discriminant analysis using 24 behavioral repertoires in three female castes (inseminated queens, non-inseminated queens, and workers) of Mycetomoellerius turrifex. Each female caste could be completely identified at a discriminant rate of $100 \%$. White squares represent inseminated queens, black squares represent non-inseminated queens, and white triangles represent workers.

\section{Discussion}

The number of queen ants is an important factor in social structure of ants. The numbers have had variable intraand interspecific, but its patterns of variation are adaptive to their environment and rarely change dramatically in a short period (Eriksson et al., 2019). Exceptions have been reported in invasive ant species, such as fire ants (Solenopsis invicta) and Argentine ants (Linepithema humile), that have been introduced to new areas as a result of human activities. These ants are known to become polygynous in invaded areas even though they are monogynous in their native areas, forming huge supercolonies in invaded areas (Helanterä et al., 2009). In my research, the continuous sampling of $M$. turrifex in Texas grasslands for three years revealed a change in the social structure from functional monogyny with a high frequency of non-inseminated queens to simple monogyny. Such social structural changes are rare under natural conditions, and might be due to the following factors: (1) environmental changes: in the summer of 1999 there was a record-breaking drought in Texas, which resulted in no successful nuptial flights, nesting, or breeding of the newly emerged alate queens. This severe drought resulted in the temporary presence of multiple noninseminated queens in the colonies. (2) Synchronization of colony dynamics: colony sizes, numbers of non-inseminated queens, brood numbers, and nest chamber depths tended to follow similar dynamics during the three years of sampling. It is likely that the dynamics of the ant populations in the region would be synchronized (Teseo et al., 2013). (3) Human impacts: the Brackenridge Field Laboratory in Austin, Texas has a limited area of $0.33 \mathrm{~km}^{2}$ and it is estimated that the population of $M$. turrifex within the area is small. Four to six colonies were sampled per year. While this is a low number, it is possible that it resulted in sampling pressure on the colonies in 2001, which may have been a factor in increasing the initial stage nests. It is difficult to determine from this study which of the three hypotheses above is the main contributor to the social structural changes in M. turrifex. It is likely that all three factors influenced the ant society.

Non-inseminated queens are very rarely found in ant colonies. Previous studies have reported a few examples of non-inseminated queens in polygynous colonies of Formica and Solenopsis (Bourke \& Franks, 1995). Only Myrmecina nipponica (Ohkawara et al., 1993; Murakami et al., 2002), Pyramica hexamera (T. Kikuchi, Associate Professor, Chiba University, personal communication, April, 2020), Probolomyrmex longinodus (Kikuchi \& Tsuji, 2005), and Acromyrmex echinatior (Nehring et al., 2012) have been found to have monogynous colonies with extra noninseminated queens. Mycetomoellerius turrifex is now the fifth ant species observed to have non-inseminated queens in a monogynous society. 
This study also shows for the first time that the noninseminated queens have a unique division of labor in the colony, and their labor repertoires are significantly different from that of the reproductive queens and the workers. Canonical discriminant analysis revealed that the factor that divided the queens into inseminated and non-inseminated ones was fungus garden care, and the factors that separated the workers from the non-inseminated queens were nest entrance defense, nest floor digging, and resting in the nest. Non-inseminated queens did not lay eggs at all and were less active in licking the symbiont fungus, which is the main food resource for queens (Quinlan \& Cherrett, 1979). Although the non-inseminated queens were more likely to engage in worker-like behaviors, their behaviors were not entirely consistent with those of the workers that defended the nest entrance by taking advantage of their large body size. These data suggest that the noninseminated queens remained in the colonies and secured their positions by undertaking a certain amount of labor.

Kikuchi and Tsuji (2005) proposed five hypotheses for the existence of non-inseminated queens: (1) mating failure due to a severe environment, (2) social parasitism to produce unfertilized male-destined eggs, (3) strategies to shift the timing of mating to the next season, (4) egg laying of trophic eggs, and (5) staying in the colony as a labor force in a worker-like manner. Three of these hypotheses are unlikely to explain the presence of non-inseminated queens in M. turrifex: (2) the social parasite hypothesis, (3) the strategy of shifting the timing of mating, and (4) the trophic egg producing hypothesis. Hypotheses (2) and (4) do not hold because the non-inseminated queens did not lay eggs during the observation period and dissections revealed that not even trophic eggs were produced in the ovarioles. Also, hypothesis (3) does not hold because the queens in the Myrmicinae have wings and mate during their nuptial flights, then they shed the wings. In other words, they are not able to conduct nuptial flight afterwards and it would be impossible to mate with males. Our data on the presence of non-inseminated queens in these ant colonies supports two hypotheses: (1) the severe environment hypothesis (due to the 1999 drought in Texas) and (5) the labor force hypothesis.

In areas at high risk of climate change, such as Texas (summer droughts, heat waves, and hurricanes), it is estimated that alate queen ants often fail to mate during nuptial flights and fail to establish new colonies. In such cases, rather than the non-inseminated queens dying, it is beneficial to the colony that they return to their mother's nest and take on labor. In particular, the relatively larger bodysize of queens would be suited to defend the nest. This is supported by the results of the present study. In contrast, the summer of 2000 had a stable climate in Austin, Texas, with a sufficiently high chance of nuptial flight and nesting. In such an environment, $M$. turrifex would be more likely to nest alone and avoid competition for resources. Therefore, the temporarily acceptance of non-inseminated queens in
M. turrifex is dependent on environmental changes, and the combination of complete monogyny is likely to be flexible enough to respond to large fluctuations in the environment.

\section{Acknowledgements}

I specially thank to Ulrich G. Mueller and his laboratory members to support the research. This research is partly supported by the grant from Japan Society For the Promotion of Science, grant number 20K06829.

\section{References}

Eriksson, T.H., Hölldobler, B., Taylor, J.E. \& Gadau, J. (2019). Intraspecific variation in colony founding behavior and social organization in the honey ant Myrmecocystus mendax. Insectes Sociaux, 66: 283-297. doi: 10.1007/s00040-019-00687-y.

Helanterä, H., Strassmann, J.E., Carrillo, J. \& Queller, D.C. (2009). Unicolonial ants: where do they come from, what are they and where are they going? Trends in Ecology and Evolution, 24: 341-349. doi: 10.1016/j.tree.2009.01.013.

Hölldober, B. \& Wilson, E.O. (1990). The Ants. Berlin, Springer, $732 \mathrm{pp}$.

Kikuchi, T. \& Tsuji, K. (2005). Unique social structure of Probolomyrmex longinodus. Entomological Science, 8: 1-3. doi: 10.1111/j.1479-8298.2005.00094.x

Mueller, U.G. \& Gerardo, N. (2002). Fungus-farming insects: Multiple origins and diverse evolutionary histories. Proceedings National Academy of Sciences, 99: 1524715249. doi: 10.1073/pnas.242594799.

Murakami, T. (1998). Sociobiological studies of fungusgrowing ants Attini: effects of insemination frequency on the social evolution. Ph. D. thesis. Hokkaido University. doi: $10.11501 / 3137226$.

Murakami, T. \& Higashi, S. (1997). Social organization in two primitive attine ants, Cyphomyrmex rimosus and Myrmicocrypta ednaella, with reference to their fungus substrates and food sources. Journal of Ethology, 15: 17-25. doi: 10.1007/BF02767322.

Murakami, T., Ohkawara, K. \& Higashi, S. (2002). Morphology and developmental plasticity of reproductive females in Myrmecina nipponica (Hymenoptera: Formicidae). Annals of the Entomological Society of America, 95: 577-582. doi: 10.1603/0013-8746(2002)095[0577:MADPOR]2.0.CO;2.

Nehring V., Boomsma J.J. \& d'Ettorre P. (2012). Wingless virgin queens assume helper roles in Acromyrmex leafcutting ants. Current Biology 22: 671-673. doi: 10.1016/j. cub.2012.06.038

Ohkawara, K., Ito, F. \& Higashi, S. (1993). Production and reproductive function of intercastes in Myrmecina graminicola nipponica colonies (Hymenoptera: Formicidae). Insectes Sociaux, 40: 1-10. doi: 10.1007/BF01338828. 
Peeters, C. \& Ito, F. (2001). Colony dispersal and the evolution of queen morphology in Hymenoptera. Annual Review of Entomology, 46: 601-630. doi: 10.1146/annurev.ento.46.1.601.

Quinlan, R.J. \& Cherrett, J.M. (1979). The role of fungus in diet of the leaf-cutting ant Atta cephalotes (L.). Ecological Entomology, 4: 151-160. doi: 10.1111/j.1365-2311.1979. tb00570.x.

Rabeling, C., Cover, S.P., Johnson, R.A. \& Mueller, U.G. (2007). A review of the north American species of the fungus-gardening ant genus Trachymyrmex (Hymenoptera: Formicidae). Zootaxa, 1664: 1-53. doi: 10.5281/zenodo.180014.
Solomon, S.E., Rabeling, C., Sosa-Calvo, J., Lopes, C.T., Rodrigues, A., Vasconcelos, H.L., Bacci Jr., M. Mueller, U.G. \& Schultz, T.R. (2019). The molecular phylogenetics of Trachymyrmex Forel ants and their fungal cultivars provide insights into the origin and coevolutionary history of 'higherattine' ant agriculture. Systematic Entomology, 44: 939-956. doi: $10.1111 /$ syen. 12370 .

Teseo S., Kronauer D.J.C, Jaisson P. \& Châline N. (2013). Enforcement of reproductive synchrony via policing in a clonal ant. Current Biology, 23: 328-332. doi: 10.1016/j.cub.2013.01.011.

Weber, N. (1972). Gardening ants, the Attines. Philadelphia, American Philosophical Society, 146 pp. 